\title{
IMÁGENES HELENÍSTICAS EN CÓRDOBA: DOS EJEMPLOS NUMISMÁTICOS
}

\author{
Miguel Ángel CEBRIÁN SÁNCHEZ
}

\section{Resumen}

En toda la Península Ibérica son escasos los hallazgos monetarios griegos orientales documentados de época helenística. Este trabajo analiza dos ejemplos numismáticos, del periodo citado, encontrados en la provincia de Córdoba. Las piezas que presentamos han de entenderse, no con sentido monetal, sino como muestras simbólicas del refinado gusto de las élites ciudadanas locales, que las utilizaban como instrumentos de adorno personal o elementos propiciadores de la fortuna en la vida terrenal y en la de ultratumba.

\section{Summary}

The Greek oriental monetary finds recorded in the Helenistic age are rather scarce all over the Iberian Peninsula. This essay analyses two numismatic examples from this time found in Cordoba. The pieces that we present have to be understood, not in a monetary sense, but as symbolic tokens of the refined taste that the local elites professed. These pieces were used as personal adornment or as elements propitiating fortune, both in this life and life beyond the grave.

\section{Introducción}

Con el presente trabajo pretendemos potenciar la investigación sobre numismática, mediante el estudio de dos monedas emitidas en los reinos helenísticos orientales y halladas, una, en la ciudad de Córdoba y otra, en las inmediaciones de la actual población de Montoro (antigua Epora). A través del análisis pormenorizado de las piezas podemos ver dos paradigmas de las intensas relaciones políticas y comerciales que se realizaron entre el Oriente y el Occidente Mediterráneo en el siglo I a. C. y una muestra del lujo (Chaves, 1991, 44) de las más pudientes clases sociales, a las que 
pertenecían estos objetos, ya desposeídos del valor liberatorio que conllevan y más próximos a las gemas, camafeos (Zazoff, 1970) y piedras preciosas que se engastaban en elementos de orfebrería, esculturas, etc.

Otra utilidad entraría en estrecha relación con su carácter exógeno, que les confiere un significado fetichista (Olmos, 1994, 43), encarnado en la propiciación de la fecundidad y la suerte a sus poseedores, de la misma manera que lo hicieron tantos objetos que portaban y adornaban los ambientes privados; también en ellos se puede intuir un remedio profiláctico contra la magia negativa (Ventura, 1996), de la que sí tenemos constancia en la Córdoba romana. Una vez que la vida llega a su término, la moneda es un elemento que acompaña en la tumba al difunto (A.A.V.V., 1992, 78) con la finalidad de propiciar el paso al otro mundo; la inclusión, de este tipo de monedas, en el ámbito funerario es una prueba más de la compleja y variada cantidad de matices que un artefacto puede contener dentro del contexto arqueológico.

\section{Circunstancias de los hallazgos}

Las dos monedas que presentamos se conservan actualmente en la ciudad de Córdoba, la tetradracma filípica en manos de un particular y la didracma ptolemaica en una colección privada ${ }^{1}$. La primera moneda a la que hemos hecho mención fue encontrada, de forma casual, en los años sesenta en el actual recinto ferial del Arenal, donde se localizaban antiguas escombreras de la ciudad. La segunda fue descubierta, de forma clandestina en 1989, en los alrededores de la actual población de Montoro, de donde pasó mediante compra a su actual propietario. No hemos podido extraer más información sobre el hallazgo de las piezas, ya que en el primer caso la persona que la encontró no dejó más datos y en el segundo caso no conocemos la identidad de los individuos que realizaron el expolio ${ }^{2}$.

Una vez localizadas las dos monedas informamos a los respectivos propietarios de la rareza que supone encontrar monedas griegas en el Occidente del Mediterráneo y de su importancia, por lo que les propusimos dejar constancia de estos hallazgos de alguna manera. Creemos que el mejor método para difundir su conocimiento es la confección y publicación de este trabajo.

\footnotetext{
' Agradecemos a los actuales propietarios J. Reyes y a la Colección Sánchez la oportunidad que nos han brindado de poder documentar estos dos ejemplos numismáticos griegos en la Provincia Ulterior.

${ }^{2}$ Nos gustaría poder expresar, en breves palabras, nuestra total desaprobación al profundo deterioro que sufre el patrimonio arqueológico andaluz por parte de las incursiones clandestinas a los yacimientos de la comunidad.
} 


\section{Descripción de las monedas ${ }^{3}$}

\subsection{Moneda número 1}

\section{Clasificación:}

Serie: Griega-helenística.

País, entidad geopolítica: reino seleúcida de Siria

Autoridad emisora: Filipo, Filadelfos.

Ceca: Antioquía ad Orontem.

Estatus: Oficial.

Material: Plata.

Nominal: Tetradracma.

Cronología: 93-83 a. C.

Referencia bibliográfica: B.M.C. 4. 100, 10.

Descripción:

Anverso: Cabeza diademada del rey Filipo (Filadelfos) a derecha, con peinado de gruesos mechones rizados y desordenados. Rodeada por gráfila de obas y perlas.

Reverso: Leyenda a derecha e izquierda del tipo, en doble línea paralela:

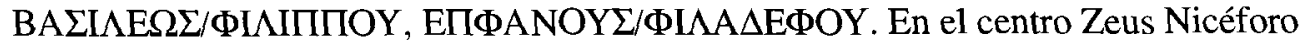
entronizado con cetro largo en la mano izquierda, la derecha sostiene una pequeña Victoria que corona al Dios con una laurea. Gráfila de hojas de laurel.

Canto: liso y anepígrafo.

\section{Datos Físicos:}

Peso: $15^{\prime} 9$ gr.

Diámetro: $20 \mathrm{~mm}$.

Giro de cuños: $1 \mathrm{~h}$.

Conservación: Excelente conservación en ambas caras.

Otros datos: aunque fue limpiada aun conserva parte de la pátina original.

Otros datos:

Bibliografía suplementaria: Newell (S. M. A.) 441, S. N. G. Vol. XII, n 427 , Grose, vol. III, $\mathrm{n}^{\circ} 9357 .{ }^{4}$

Observaciones: Encontrada casualmente en Córdoba. Pieza Inédita.

\footnotetext{
${ }^{3}$ Para clasificar las monedas hemos seguido el método utilizado por Marta Campo en su obra: (1987) Numismática, dades per a la documentació numismàtica, Barcelona.

${ }^{4}$ Sylloge Nummorum Graecorum. Italia. Civiche Raccolte Numismatiche, Milan. Grose, S. W. (1979) Catalogue of the McClean Collection of Greek Coins, Chicago.
} 


\subsection{Moneda número 2}

Clasificación:

Serie: Griega-helenística.

País, entidad geopolítica: reino Lágida de Egipto.

Autoridad emisora: Ptolomeo V.

Ceca: Alejandría.

Estatus: oficial.

Material: Plata.

Nominal: didracma.

Cronología: 204-180 a. C.

Referencia bibliográfica: Grose, vol. III n 3.244 .

Descripción:

Anverso: Cabeza diademada de Ptolomeo $\mathrm{V}$ a derecha con peinado en gruesos mechones serpenteantes. Gráfila de puntos.

Reverso: Leyenda circular ПTO $\Lambda$ MAIOY/BA $\Sigma I \Lambda E \Omega \Sigma$, en el centro águila a izquierda sosteniendo en sus garras un haz de rayos. Gráfila de puntos.

Canto: liso y anepígrafo.

Datos físicos:

Peso: 6’5 gr.

Diámetro: $15,5 \mathrm{~mm}$.

Giro de Cuños: $1 \mathrm{~h}$.

Conservación: Excelente conservación en ambas caras.

Otros datos físicos: fue eliminada su pátina inadecuadamente con ácidos.

Otros datos:

Bibliografía suplementaria: Svoronos 1.210. S. N. G. 245.

Notas y observaciones: encontrada clandestinamente en las inmediaciones de Montoro (Córdoba).

\section{Conclusiones}

Las dos monedas que presentamos en este articulo pretenden contribuir a un mejor conocimiento de las relaciones entre el Oriente y el Occidente del mar Mediterráneo y más concretamente a paliar la pobreza de materiales numismáticos helenísticos recogidos en la bibliografía española. 
Para la moneda número 1 debemos tener en cuenta tres datos importantes de cara a asignarle una funcionalidad, ya que estamos convencidos de que el ejemplar había dejado de tener valor de cambio: en primer lugar, sabemos que la moneda está asociada a una cronología Post quem del 93-83 a. C., fecha del reinado de Filipos en Siria; el segundo dato a tener en cuenta es su aparición en Córdoba capital, y por último hemos percibido que la moneda no presenta restos de soldaduras ni vanos para su engarce (Perea, 1991, 25-30) con otros elementos. Todo lo anterior nos conduce a pensar que la moneda en cuestión debió de ser utilizada, a partir de la segunda mitad del siglo I a. C., como elemento de lujo posiblemente relacionado con el fetichismo y la propiciación de la Fortuna ante las vicisitudes de la vida terrenal.

Cuando nos acercamos a las circunstancias inherentes a la pieza número 2 comprobamos que hay diferentes datos para centrar la moneda en su lugar y su tiempo. Para esto hemos creído conveniente resaltar las siguientes observaciones: La cronología de esta pieza es considerablemente anterior a la pieza antes referida, 204-180 a.C.; su localización remite a una zona del sur de la provincia de Córdoba, en los alrededores de Montilla (antigua Epora); y, la anterior moneda no presenta muestras de soldaduras ni vanos. Por ello creemos que esta pieza pudo estar asociada al mundo funerario, como ajuar de alguna tumba ibérica, hecho éste parangonable a otros descubrimientos realizados en el sureste hispano (Sánchez Jiménez, 1949). Cronológicamente, podemos pensar que la llegada al sur de la Península Ibérica de este tipo de acuñaciones puede ser relacionado con los últimos momentos de la segunda Guerra Púnica (Chaves, 1990, 617) -tanto por parte del bando cartaginés como por parte del ejercito de Escipión (Crawford, 1985)-, época en la que se atestigua para Epora una trabajo de laboreo y transporte de metal desde las minas de Sierra Morena hasta la costa de Málaga (Rodríguez Neila, 1992, 29),siendo el ejercito cartaginés el portador idóneo para traer este tipo de monedas a Occidente.

Los excelentes retratos que presentan las acuñaciones aquí estudiadas, no son los únicos que se pueden encontrar en la Córdoba republicana romana. La existencia de una cabeza hermaica en el Museo Arqueológico Provincial de Córdoba $\left(\mathrm{n}^{\circ}\right.$. de inventario: 30.143), que según las últimas investigaciones (Loza, 1996, 259-268) encajaría con la de un príncipe helenístico, es un ejemplo más del distinguido gusto que caracteriza a las clases altas de la Corduba republicana y de ámbitos más reducidos, como correspondería a la población de la Montilla de finales del siglo III comienzos del II a. C.

No queremos cerrar este trabajo sin llamar la atención sobre los todavía limitados resultados de la investigación numismática en la provincia de Córdoba, también por lo que a la localización de hallazgos se refiere. Este artículo ha querido contribuir a paliar la falta y a animar a que en un futuro cercano puedan emprenderse investiga- 
ciones que contribuyan a un mejor conocimiento de la realidad arqueológica a través de los hallazgos numismáticos ${ }^{5}$.

\section{BIBLIOGRAFÍA}

A.A.V.V. (1927): British Museum catalogue of greek coins (B. M. C.), London. A.A.V.V. (1992): Griegos en Occidente, Sevilla. A.A.V.V. (1992): La sociedad ibérica a través de la imagen, Madrid. A.A.V.V. (1996): Colonia Patricia Corduba, una reflexión arqueológica, Sevilla. A.A.V.V. (1996b): Córdoba en tiempos de Séneca, Córdoba..

ALMAGRO GORBEA, M. ; OLMOS, R. (1981): “Observations sur l'assimilation de l'iconografie classique d'époque préromaine dans la Péninsule Ibérique», Colloques Internationaux du Centre National de la Recherche Scientifique, $\mathrm{n}^{\circ}$ 593, 57-66..

BURNETT, A. M. (1983): “ Rome et le monde hellènistique", Monnaies du monde entier, Paris.

CALLATAY, F.; DEPEYROT, G.; VILLARONGA, L. (1993): L'argent monnayé d'Alexander le Grand á Auguste, Bruxelles.

CAMPO, M. (1987): Numismática, dades per a la documentació numismática, Barcelona.

CHAVES, F. (1990) : "Los hallazgos numismáticos y el desarrollo de la II Guerra Púnica en el sur de la Península Ibérica”, Latomus, 49, pp. 613-622.

-: (1991): "Elementos numismáticos de índole griega en la Península Ibérica", Habis, $22,27-48$.

CRAWFORD, M. (1985): Coinage and money under the Roman Republic Italy and the Mediterraneam economy, London.

FRANKE, P. R.; HIRMER, H. (1964): Die griechische münze, München.

FRASER, H. (1972): Ptolemaic Alexandria, Oxford.

\footnotetext{
${ }^{5}$ Queremos agradecer al Profesor Dr. Don Pere Pau Ripolles Alegre de la Universitat de València su ayuda a la hora de orientarnos en la clasificación de las monedas, así como sus acertadas opiniones, de igual forma, agradecemos al Profesor Dr. Don Desiderio Vaquerizo Gil de la Universidad de Córdoba sus sugerencias a la hora de realizar este trabajo.
} 
FURTWÄNGLER, A. E. (1978): Monnaies grecques en Gaule, Basel.

GIARD, J. B. (1971): "L'art du portrait sur les monnaies romaines", Graveurs d'acier et la medaille, $97 \mathrm{y}$ ss.

GIOVANNINI, A. (1978): Rome et la circulation monétarie en Grèce au II siècle avant Jésuchrist, Basel.

GORINI, G. (1992): "La presenza greca in Italia settentrionale: La documentazione numismatica", Griegos en Occidente, 91-114.

HERRERO, C. (1994): Introducción a la numismática antigua Grecia y Roma, Madrid.

KRAAY, C. ; HIMER, M. (1976): Archaic and classical greek coins, London.

LACROIX, L. (1949): "Les reproduction de statues sur les monnaides grecques", $L a$ stautaire archaique et classique, Paris.

-:(1965): Monnaies et colonisation dans l'Occident grec, Bruxeles.

LE RIDER, G. (1958): "Sur la fabrication des coins monétaires dans 1'antiquité grecque", Sweizer Münzenblatter 8, 52-132.

PEREA, A. (1991): Orfebrería prerromana, Madrid.

RICHTER, G. M. A. (1984): The portraits of the greeks, Oxford.

RODRIGUEZ NEILA, J. F. (1992): "Problemas sobre la protohistoria y romanización de la antigua ciudad de Epora (Montoro)", Montoro historia y arte, 1992.

SANCHEZ JIMENEZ, J. (1949): “Tetradracma del Llano de la Consolación (Albacete)", IV Congreso Arqueológico del Sureste: 34-41, Elche.

SVORONOS, J. (1908): Ta nomismata tou kratous ton Ptolemaion, Athens.

VENTURA, A. (1996): "Magia en la Córdoba romana", Anales de Arqueología Cordobesa, 141-162.

ZAZOFF, P. (1970): Antiken gemmen in deutchen sammlungen, Weisbaden. 


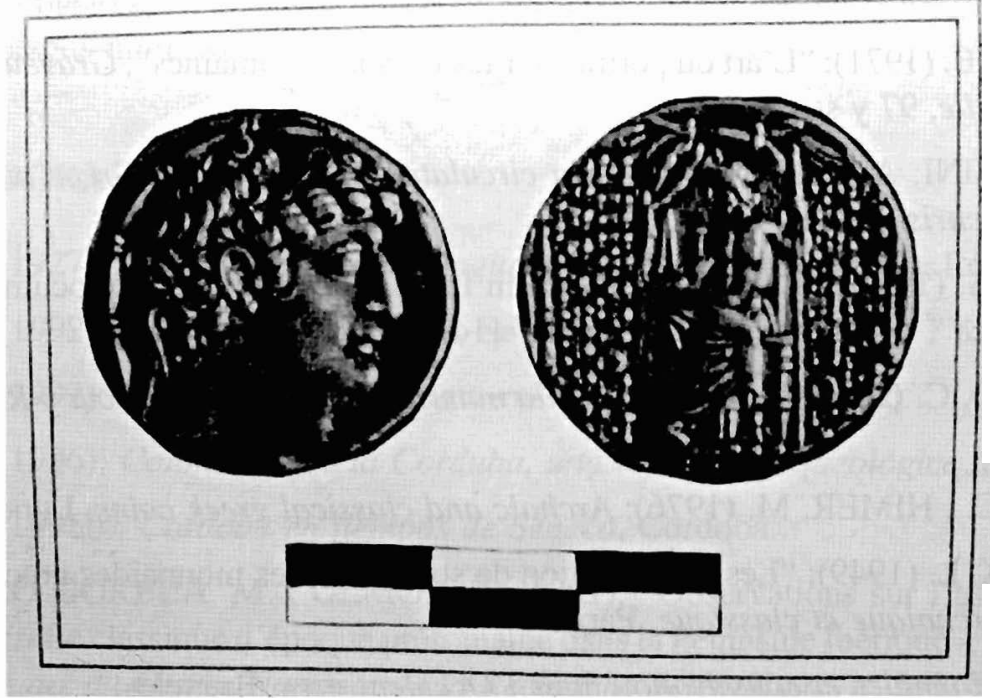

Lám. 1: Tetradracma de Filipo, Filadelfo

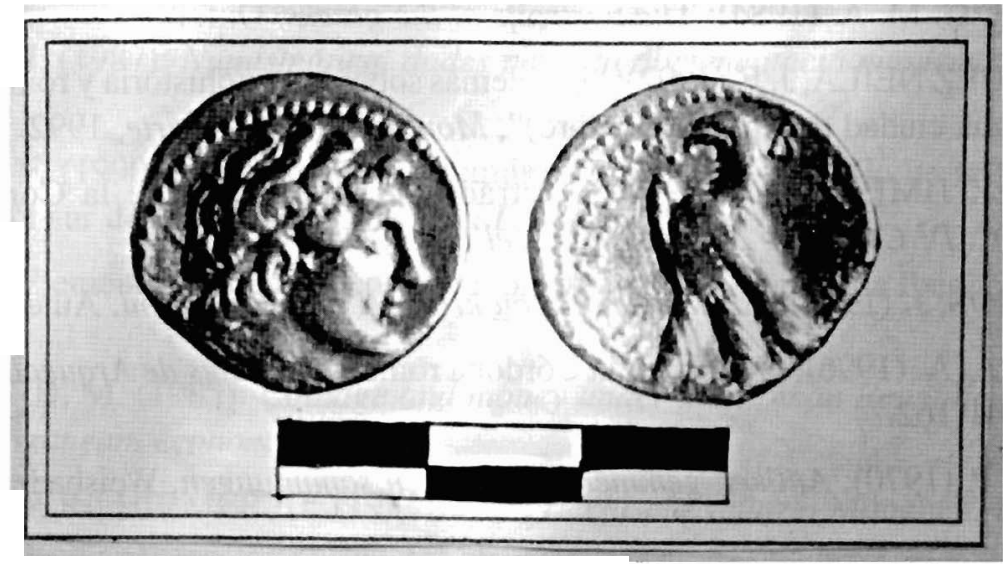

Lám. 2: Didracma de Ptolomeo V 